\title{
Global Leadership Education: Upping the Game
}

\author{
Elizabeth Goryunova \\ Assistant Professor \\ Leadership \& Organizational Studies \\ University of Southern Maine \\ elizabeth.goryunova@maine.edu \\ Daniel M. Jenkins \\ Chair and Associate Professor \\ Leadership \& Organizational Studies \\ University of Southern Maine \\ daniel.m.jenkins@maine.edu
}

\begin{abstract}
While scholars recognize that digital technology is a major tool employed by contemporary learners to access knowledge, its full capacity is yet to be utilized. This paper investigates opportunities to increase individual learning engagement and knowledge retention in higher education and corporate environments through integrating educational content with innovative digital technology. Currently, within commonly adopted e-learning platforms, the most utilized online content delivery and student progress assessment tools in leadership education appear to be discussion-based instruction, along with written assignments, and research projects (Jenkins, 2016). To inform leadership educators' choice in innovative tools for increased effectiveness of instruction, this paper shares an experience of delivering integrated global leadership education pedagogical content (i.e., cross-cultural competency instruction for graduate management class at a U.S.-based public university) within a gamified real-time multiuser learning platform-MyAltis — and discusses implications for leadership education.
\end{abstract}

\section{Introduction}

Along with recent growth in distance and technology-enhanced learning, online leadership education programs have revealed a unique array of instructional and assessment strategies (Jenkins, 2016; Phelps, 2012). As well, today's students, Millennials (gen Y) and postMillennials (gen $\mathrm{Z}$ or i-gen), incorporate a great deal of digital interaction into their lives. Consequently, the educational needs of "digital natives" are better served by instruction based on innovative (gamified, among all) technology applications (Gee, 2003; Mastroianni, 2016; Prensky, 2001). While research demonstrates the benefits of gamified instruction for improved student engagement and learning outcomes (Damian et al., 2015; Huebscher \& Lendner, 2010), it is currently underutilized and largely delivered in the form of custom games/simulations designed for a specific university or discipline, that is generally not transferable across learning domains. For instance, the Yield Management Game is an instructor resource offered as part of a Service Management Operations textbook (Fitzsimmons, 2014), Stanford university offers an Energy Market Game (Energy Market Game, 2017), and a variety of mannequin-based simulations are offered at the Medicine Center for Immersive and Simulation Based Learning 
(Stanford Medicine, 2017). At the same time, educational institutions widely subscribe to a variety of standardized digital learning management systems (e.g., Blackboard, Canvas, WebCT) that are used for administering tests, as a repository of instructional materials, and as a communication channel between faculty and students. Yet, most recent efforts in educational technology are focused on achieving interoperability of available digital technology tools, such as finding ways to integrate gamified instruction as self-contained learning objects within learning management systems (LMS) (Burgos, Tattersall, \& Koper, 2007; Torrente, 2009). Through this application paper, we aim to address practical facets of digital gamified instruction, specifically for leadership education, implemented in a graduate management classes at a U.S.based public university (with mostly Millennial students). We begin with an overview of the current state of leadership education and then identify recent global leadership research that effectively informs existing global leadership education content. Further, we address select emergent technologies that stimulate individuals' learning process engagement and knowledge retention. This expedition concludes with an exploratory integration of educational content with innovative technology to increase effectiveness of global leadership education programs/corporate training worldwide.

\section{A Pipeline for Global Leadership Education}

According to the U.S. Census Bureau, in 2015, Millennials (gen Y) became the nation's largest living generation at 83.1 million (U.S. Census, 2015). Additionally, a Brandon Hall Group study (2015) found that $15 \%$ of Millennials presently serve in management roles, while $53 \%$ of Millennials aspire to take on a leadership role within their current organization in near future. Yet, according to a recent Deloitte study, 30\% of Millennials stepping into leadership roles do not feel fully prepared to lead (Deloitte, 2014).

Leadership development is identified as a number one concern by two-thirds of 500 executives polled by McKinsey in 2014. Likewise, according to Brandon Hall (2015), 84\% of organizations anticipate a shortfall of qualified leaders over the next five years. As closing leadership skill gap remains among the top priorities of organizations, annual leadership development training expenditures of U.S. companies approached \$14 billion in 2012; and neared \$12,210 per executive in 2014 (Deloitte Leadership Development Factbook, 2012, 2014). Yet, according to the recent study of the industry "watchdog" Institute for Corporate Productivity (i4CP), effectiveness of corporate global leadership development programs diminishes year after year (i4CP, 2014). Similarly, the McKinsey Quarterly reported that, in 2014, only 19\% (down from $42 \%$ in 2010) of polled U.S. business executives, and $7 \%$ of U.K. senior managers, rated their corporate global leadership development as effective (Gurdijian, Halbeisen, \& Lane, 2014). As a result, a growing number of corporations turn to "content experts" for development and delivery of global leadership development programs--fom 55\% in 2010 to $80 \%$ in 2012 (American Management Association, 2012). 
As recognized expert content providers, higher education institutions offer a variety of executive training opportunities, where the cost of a customized leadership development program at a prestigious institution could reach $\$ 150,000$ per trainee (Gurdijian et al., 2014). At the same time, higher education institutions are uniquely positioned to serve as a cradle for future leaders by offering leadership development programs and opportunities to their enrolled students. Today's learners seek flexible, accessible, and cost effective educational opportunities. To match these needs, institutions of higher education must augment their leadership development programs with innovative instructional technology. Yet, overall, universities and colleges are lagging in delivering effective leadership education programs, and the pipeline of future global leaders remains weak (Jenkins, 2012). Consequently, leadership education scholars and global leadership practitioners are looking for ways to improve the effectiveness of higher education global leadership education programs.

\section{A Digital Disconnect in Leadership Education}

Research-based evidence indicates that when appropriately integrated with curriculum, games offer active learning components, group collaboration, and consequently increase learner's engagement and outcomes (McFarlane, 2002; Wolfe, 1997). Consequently, over the last 20 years, games have been introduced into traditional instruction in a variety of ways - for example, board, paper, and various in-class simulations (Guest, 2015). Most recently, games based on digital technology are attracting attention of educational specialists and researchers as a new knowledge distribution channel, rather than entertainment (Wang, Li, \& Tzeng, 2015).

As reported by the Chronicle of Higher Education (2011), most of today's students (a) own various laptops and internet-capable handheld devices; (b) feel that technology incorporation improves convenience and quality of their learning experience; and (c) like to use technology to learn. In 2009, children between the ages of eight and eighteen packed almost eight hours of media content per day (Rideout, Foehr \& Roberts, 2010). At the same time, instructors' use of technology ranges between five and twelve percent, while close to $60 \%$ of instructors are stressed by trying to keep up with information technology developments. Therefore, one of our most urgent education effectiveness issues is a digital-technology-induced disconnect between the way today's students think and process information and the way instructors relate to digital technology (i.e., "digital natives" vs. "digital immigrants") (Prensky, 2001).

Today's students spend more than twice as much time annually playing video games (10,000 hours) than reading books (Prensky, 2001). Moreover, if you were born after 1980 (Millennials/gen Y and post-millennials: gen $\mathrm{Z}$ or i-gen), gaming has been and will continue to be an integral part of your life (New Media Consortium, 2012). A recent industry study reported that there are roughly 700-million gamers worldwide, or $17 \%$ of the world's population (SpilGames, 2013). Likewise, a Horizon report of the New Media Consortium (NMC - an international community of experts in educational technology) estimated the number of people in the U.S. engaged in online games in 2011 as close to 62-million, where 40\% are 20-34 years old.

Gaming appeals to individuals because it offers an opportunity to problem-solve, collaborate, work towards a goal, and be rewarded with a spectacular success within the storyline 
provided (NMC, 2012). At the same time, scholars caution against using technology for its own sake, particularly when there is no clear tie to educational content (Guthrie, Phelps, \& Downey, 2011; Jenkins, Guthrie, \& Endersby, 2015; Jones \& Cuthrell, 2011; Lei, 2010; Moody, 2010). Specifically, scholars argue that, to be effective as a learning tool, a gamified experience should meaningfully align educational and cognitive components (Dickey, 2005; Gee, 2003; Wideman et al., 2016). Thus, when applied to training in medical and information systems domains of expertise, gamified learning resulted in increased learners' motivation and superior learning performance (Papastergiou, 2009; Wang et al., 2015).

When intelligently integrated with educational content, computer games can create an environment that is both beneficial and attractive for today's learner-engaging (e.g., roleplaying/avatars, advancement towards a higher achievement level, immediate feedback on player's activity, and increased student comprehension), flexible, accessible on demand, and cost-effective. And, while some educators suggest that game-based learning is faulty, Gee (2003), argues that good games "build into their designs and encourage — good principles of learning, principles that are better than those in many of our skill-and-drill, back-to-basics, testthem-until-they-drop schools" (p. 205). Likewise, Prensky (2001) advises that incorporating well designed educational games into learning environments may help "digital natives" to learn (improve learning outcomes) by "speaking their language".

As mentioned earlier, for Millennials, the mastery of digital technology tools is a part of their identity. Therefore, as growing number of Millennials enter leadership positions and require leadership development, leadership educators are looking into incorporating engaging digital technology (specifically, gaming) into leadership education curriculum. For instance, Guthrie et al. (2011) suggests that a combination of theory and situated learning (Lave, 1988) with experiential learning (Kolb, 1984) provides a foundation for building virtual-reality/game based leadership development opportunities. Keeping this in mind, leadership educators must seek to customize gamified educational content to fit individual backgrounds and learning styles of today's learners.

\section{The Educational Content of a Digital Global Leadership Education Platform}

Within the domain of leadership education, leadership in the global context has been a subject of intense attention since the late 1990s. Accordingly, scholars recognize the following core dimensions of global leadership: (a) contextual (complexity, multidimensionality); (b) relational (boundary spanning, information flow); and (c) spatial-temporal (required physical presence in host cultures) (Mendenhall, Reiche, Bird, \& Osland, 2012). Further, within those dimensions, numerous attributes of successful global leaders have been identified, examined, and utilized as a foundation for educational and training programs. Thus, strategy, organizational/industry expertise and visioning are recognized as common attributes of effective leaders (global or not), while intercultural competency is considered critical attribute specific to global environment, as it- enables leaders to effectively interact with peers, stakeholders and subordinates in a multi-cultural environment (Beechler \& Javidan, 2007; Bird, Medenhall, Oddou, \& Stevens, 2010; Goldsmith, 2000; House, Hanges, Javidan, Dorfman, \& Gupta, 2004; Mendenhall, Osland, Bird, Oddou, \& Maznevski, 2008; Moro \& Tubbs, 2004). 
In a modern culturally diverse environment, intercultural competency enables influence and coalition building, a skill that a 2012 American Management Association (AMA) industry study listed (along with critical thinking) as the most sought-after attribute of global leaders. Similarly, a study conducted by the University of North Carolina (UNC) Kenan-Flagler Business School listed multi-cultural sensitivity/awareness and strategic thinking among the top competencies of global leaders (UNC, 2015).

The AMA predicts that, over the next ten years, the core competencies critical for global leaders will remain largely consistent, yet with a stronger emphasis on inter-cultural aspects of the job and the use of technology (AMA, 2012). And, while the menu of desirable traits of global leaders exceeds 60 (Beechler \& Javidan, 2007; Goldsmith, Walt, \& Doucet, 2000; House et al., 2004; Mendenhall et al., 2008; Moro \& Tubbs, 2004), intercultural competency and critical thinking are consistently included by studies among the most important. Consequently, these traits should represent principal components of effective global leadership education programs.

\section{Metacognition and Critical Thinking in Global Leadership Education}

Intercultural competency and critical thinking appear as distinctly different concepts, yet a review of the research suggests that an intrinsic connectedness through the construct of metacognition. Metacognition, in general, is a higher order thinking skill, often referred to as "thinking about thinking". The term metacognition was introduced in educational context by Flavell (1976) to define active monitoring, regulating, and directing of individual cognition to achieve specific objectives. In turn, Hennessey (1999) emphasizes the strategic nature of metacognition, characterizing it as an "active monitoring of one's cognitive processes and application of a set of heuristics as an effective device for helping people organize their methods of attack on problem in general" (p. 4). Metacognition is especially critical in a complex environment because it enables individual to analyze, make sense of the environment and one's actions, learn and problem-solve (Mathan \& Koedinger, 2005; Sternberg, 1985), utilize cognitive skills to achieve the greatest possible task outcome (Geiwitz, 1994), and ensure individual ability to apply knowledge acquired in a specific context across other contexts/domains (PapaleontiouLouca, 2003).

In a complex global cross-cultural context, metacognition enables monitoring and understanding of how one's own cognition relates to cognition of others, facilitating effective interaction and culture-appropriate behavior (Earley \& Ang, 2003; Thomas et al., 2008). Metacognition is considered to be an integral part of Cultural Intelligence (CQ), a multidimensional construct introduced by Earley and Ang (2003) to describe individual ability to recognize cultural differences and adapt to unfamiliar cultural contexts. Earley and Ang identified the four dimensions of CQ as (a) cognitive; (b) motivational; (c) metacognitive; and (d) behavioral - however, the interrelationship between the dimensions remains indistinct. More recently, Thomas et al. (2008) addressed this deficiency by introducing a modified model of CQ where metacognition serves as its central processing engine.

According to Thomas et al. (2008), as a core dimension of CQ, metacognition "translates" individuals' cognitive inputs into behavioral outputs and transfers acquired cognitive knowledge across cultural domains. In other words, individuals engage their metacognition in 
order to respond to a feedback from dynamic environment and facilitate effective adaptation (Brown, 1987; Flavell, 1979, 1987; Urban, 2012). Relatedly, Molinsky (2007) refers to the act of adapting one's behavior to match the other culture appropriate norms as "cross-cultural codeswitching". Additionally, Kuhn (2000) suggests that at the highest level of metacognition, the individual has a repertoire of strategies to consistently and appropriately draw upon, implement, monitor and evaluate success.

Empirical studies suggest that metacognition is a critical determinant of an individual's ability to factor environmental feedback into decision making, recognize and analyze multiple decision frameworks, ensure selection of the best available decision, and ensure cross-cultural effectiveness (Schraw \& Dennison, 1994; Thomas et al., 2008; Urban, 2012). Additionally, Day, Fleenor, Atwater, Sturm, and McKee (2014) suggest that metacognitive training can influence the development of leaders' mental models as well as social intelligence and tacit knowledge, resulting in enhanced adaptive performance. Accordingly, Day et al. (2004) recommend incorporating metacognition-enhancing instruction into global leadership training programs.

Leadership and education scholars concur that metacognition is closely related to (and even overlaps with) critical thinking, yet their opinions differ in perception of the relative ascendancy and domain of the constructs. For instance, Flavell (1976) considers critical thinking to be a part of metacognition, Willingham (2007) suggests a facilitating function, that is, "metacognitive strategies, once learned, make critical thinking more likely" (p. 17), and Day et al. (2014) refer to metacognition as an executive level critical thinking skill.

Until recently, metacognition and critical thinking were largely overlooked by traditional education - that is primarily focused on delivery of cognitive knowledge. As Paul (1993) offered in his analysis of the state of critical thinking in education: "To this day we commonly teach as if mere recall were equivalent to knowledge" (p. viii). Instead, metacognition and critical thinking can and should be taught, especially in leadership education programs. According to Jenkins (2012), in a global environment, businesses, schools, and international relations depend on critical-thinking skills of global leaders. Consequently, Jenkins (2012) argues that educators must integrate critical thinking instruction in global leadership curriculum. Likewise, Day et al., (2014) emphasize the importance of metacognitive training for leaders' performance.

Common elements of critical thinking and metacognition emerge from the research, such as analyzing and evaluating information/feedback, making inferences/decisions, and solving problems (Case, 2005; Ennis, 1985; Lai, 2011; Paul, 1992; Willingham, 2007). There are also commonalities in the ways critical thinking and metacognition can be taught. For instance, critical thinking can be taught through (a) deliberate practice (on real-life problems); (b) infusion (critical thinking within subject matter instruction); (c) immersion (real-life problems without explicit focus on critical thinking); and the most successful (d) mixed approach (explicit instruction on critical thinking along with content-integrated) (Adelman et al., 2000; Lai, 2011; Willingham, 2007).

Likewise, metacognition can be enhanced through deliberate practicing of metacognitive strategies that are effective for achieving a specific objective (Flavell, 1979; Mor, Morris, \& Joh, 2013). Thus, to increase effectiveness of functioning across cultures, individuals could benefit 
from practicing metacognitive strategies, such as cultural perspective taking (Mor et al., 2013), "radiating empathy" (Goryunova, 2016, p. 64), adjusting one's behavior to match cultural schemata of the counterpart and monitoring interaction for signs of positive/negative "feedback", verbal or non-verbal (Goryunova, 2016).

In sum, global leadership education programs could benefit from instruction on crosscultural competence, that includes, among all, enhancing metacognition and critical thinking by practicing specific strategies and behaviors. Consequently, next, we will explore strategies that integrate training with common elements of critical thinking and metacognition into a format uniquely suitable for today's learner-digital global leadership education instruction.

\section{Integration of Global Leadership Education Content with Gamified Platform}

As discussed earlier, enhancing cross-cultural competency results in improved effectiveness of global leaders. Today's and Tomorrow's leaders, as digital natives, benefit from instruction that incorporates digital component/platform. Digital educational platforms - also known as Learning Management Systems (LMS) - are defined as "a software application that automates the administration, tracking, and reporting of training events" (Ellis, 2009). A majority of commonly utilized LMS (e.g., Blackboard, Canvas) are primarily focused on efficiency of the learning process, as viewed from the perspective of instructors and administrators. Thus, according to a Learning Circuits 2009 users' survey, the most valuable features of traditional LMSs reported by users included analytics, assessment and testing, content management, course catalog, and other administrative functions.

While traditional LMS have been around for a while, empirical research (Wang et al., 2015) demonstrates higher efficiency and higher learning performance (as compared to traditional web-based learning) of gamified (game- based learning) platforms. Wang et al. (2015) argue that in order to achieve higher learning outcomes, learners have to experience cognitive process along with actual knowledge acquisition. That is, factual knowledge can be achieved by learners through a series of "remembering and understanding" processes typical for a gamified environment. Wang et al. (2015) propose a learning experience model that incorporates three essential game components: tool, feedback, and goal. Based on a three-phase experiment with a certification program for university sophomores, gamified educational intervention is not only an effective training tool, but (from students' perspective) a desirable one that can be expected to improve learning performance (Wang et al., 2015). While Wang et al. (2015) developed and tested their own gamified learning model, we adapted the existing gamified learning platform MyAltis, initially developed for a corporate environment, to the graduate management curriculum at a U.S.-based public university. Here, we share our experience with MyAltis with an aim to raise the awareness of leadership education practitioners and researchers about innovative tools available for leadership education.

\section{Overview of Gamified Platform: MyAltis}

MyAltis is a learner-centered real-time multiuser gamified digital platform that offers elements of the game (tools, feedback, goal) delivered in engaging gamified learning environment. In MyAltis, a learner's experience is enhanced through a combination of interactive 
features including role-playing, immediate interactive feedback on player's activity and comprehension, advancement towards a higher achievement level, and virtual rewards (trophies). Additionally, the platform offers an opportunity to develop virtual networks and collaborate on tasks in a flexible, on demand learning environment that empowers today's learners to access content anywhere, anytime.

In terms of utility, MyAltis can be utilized as a self-sustained gamified LMS or incorporated into existing LMS as an engaging gamified component. Essentially, it offers the same range of learning management tools as traditional LMS. Yet, unlike most LMS, MyAltis is focused on learner's experience defining it as "entertraining revolution" ( ${ }^{\mathrm{TM}}$ ). Moreover, the MyAltis Virtual Training Center is a real-time multi-user application that can be configured in accordance with customers' (universities/organizations that administer instruction) specifications to include "rooms" dedicated to a particular type of instruction (e.g., a library, game room, video room, board room, etc.). Every room in the Virtual Center is populated with numerous interactive objects that offer guidance and/or access to specific educational content. For instance, a coffee machine in the Reception Area is linked to the Training Center Social Network that is utilized for knowledge sharing, collaboration, and social interaction, and can be accessed with individual credentials.

The menu of learning management tools and games within MyAltis is universally applicable to any discipline/educational content, whether it is a nutritional science or leadership development. Customers can populate the platform with desirable content and, based on that content, build learning paths to accommodate individual or group-specific learning objectives. Additionally, when appropriate, learners can self-register for the educational content of their choice (learning path) through the Registration Desk of the Virtual Center. Each learning path consists of three integral components intertwined to create rich learning experience: (a) pedagogical content; (b) quizzes; and (c) social networks. The learning process and outcomes are managed and measured with comprehensive analytics such as detailed data and charts on learners' performance and progress.

On the user side, the engagement begins with an opportunity for learners to design their own avatars - that appear within the Center in real time - to follow the learning path assigned to them by instructor and complete assigned tasks as well as gamified quizzes. As in every gamified real-time multiuser environment (e.g., SecondLife), within Virtual Training Center, learners can identify each other by avatars, interact with one another individually via instant messaging or collaborate as a team. Gamers are known for their emergent communities of practice that distribute knowledge and social "capital". Accordingly, MyAltis disrupts the common "isolation effect" experienced by learners in a traditional online educational environment and builds their network/team skills through virtual community interaction, sharing practice and information, while offering gaming format that does not jeopardize the actual training objective.

Application of MyAltis for Cross-Cultural Competency Instruction. As a part of a graduate management curriculum, authors piloted MyAltis as a platform for cross-cultural competency instruction, where enhancing cross-cultural competency is a learning outcome achieved through various instructional components as well as practicing critical thinking in analysis of real-life scenarios. Specifically, upon accessing this application, the learner 
undergoes gamified testing ("profiler") of his/her existing cross-cultural competence levels. After the game/test is over, upon receiving individual score/feedback, the learner is empowered to explore the Virtual Center and access various components of instruction (pedagogical content) through interactive objects within the Center. We have observed that students appreciate ability to control their "virtual existence" and enjoy "freedom of movement" within the Center. Pedagogical content for the Global Leadership Education cross-cultural competence course consists of educational texts, presentations, videos, and tests, all preloaded into the platform and further grouped into distinct steps of the learning path (sequence of steps is customized to fit specific learner's objective), with gamified interaction integrated into each of its components. For instance, the "Chapter 1 Introduction to Cultural Awareness" step, consists of a gamified quiz to measure learner's level of cultural awareness, an introductory text on the same topic, a video illustrating cultural differences, and a social network discussion forum. Additionally, learners' avatars can schedule the Center's Board Room for a meeting, get together in the Video Room to watch media, discuss and collaborate on the assigned paper in real time, or complete their tasks individually.

When designing a learning path, instructors can choose between sequential structure (where each learning step must follow a predetermined order) and a simultaneous one (where learners determine the sequence of existing steps). In our experience, the simultaneous path is more effective as it emphasizes decision-making in learners' educational processes by offering students more flexibility and control over their learning. For instance, in the "Chapter 1" step, learners can "teleport" their avatars to any of the scheduled destinations of their choice: (a) to the library (to read the text); (b) to the theater (to watch the video); (c) to the Game Room (to attempt the quiz); or (d) they can select any other steps throughout the entire learning path.

While the simultaneous learning path makes all content available to the learner all the time, the proposed sequence of steps within the learning path indicates the optimal study progression, with intermittent gamified tests strategically positioned throughout the learning path for learners to practice their skills. For instance, in our courses, presentations and readings on cultural dimensions are placed in modules preceding the gamified test to practice critical thinking/metacognitive skills on real life cultural scenarios. At the same time, students may choose to take test without going through recommended instruction if they are confident in their skills.

Each scenario within the gamified test is presented to learners one at a time. Thus, during the "InSitu" game, a virtual facilitator (avatar) invites learners to apply critical thinking skills to evaluate underlying motivations for behavior in a hypothetical cross-cultural situation:

You are making a proposal to a group of Japanese Executives when you notice a few of them sat with their arms folded and eyes closed. They are: (a) Praying; (b) Listening intently; (c) Tired and catching up on some sleep; or (d) pretending to be asleep to show you that they think your presentation is poor.

Learners then apply their critical thinking skills and cognition to analyze the situation and make determinations on motivations. Immediately following, learners receive feedback on their decisions (approval of disapproval) from the avatar/virtual facilitator. 
Feedback on individual performance is extremely important to students, no matter the discipline. Specifically, when applied to situational assessment (motivation determination), immediate feedback is observed to prompt learners to re-evaluate their cognitive knowledge and re-apply their critical thinking skills to achieve accurate outcome. As observed by authors, who administered tests in both traditional settings and through MyAltis, the immediate individual feedback offered by MyAltis virtual facilitator to each student's answer creates efficiencies in a learning environment that are hardly possible to achieve in a traditional setting, especially in a large class. We have successfully utilized MyAltis to administer tests to students individually, as well as in a group (in a traditional and/or blended-delivery class setting) where the test progresses on a classroom video-screen, allowing students to participate in an open and active discussion of scenarios.

Additionally, to enhance students' ability to transfer knowledge across different contexts, we utilized MyAltis game collection to build critical thinking skills exercises across games of diverse types and structures: InSitu, multiple choice, score, and true/false. Depending on the type of the game, learners may either receive instant feedback for each answer, or the tallied-up report at the end of the game that includes achievement level, how individual score is measured against learner's individual objective, and a learner's "global" ranking for a game. High score results in a virtual trophy awarded to the learner to be displayed in their account. Arguably, taking fear out of the "test equation" helps students focus more on educational content, rather than on possibility of making a mistake. Thus, if learners are not satisfied with their current achievement level, they can start "the game" over, repeating the critical thinking process, and learning to make accurate judgments and correct potential mistakes without suffering serious "real-life" consequences. Alternatively, in a true game fashion, the "scoring" game offers students additional help in identifying the right answer with an option to eliminate two wrong answers out of four available for review. We have observed that, while students develop individual preference to one game over another, they overall favor any gamified test over the traditional one because of the element of fun it brings into their learning--they cheerfully refer to the available gamified tests as their "lives left".

In addition to engaging educational content, the social aspect of the gamified environment should not be overlooked. Social interactions are recognized as an important component of situated learning (Guthrie, 2011; Lave, 1988). Accordingly, collaborative learning structures and social interactions are known to promote cognitive development and metacognitive skills (Dillenbourg, Baker, Blaye, \& O’Malley, 1996; Hennessey, 1999; Lai, 2011; Martinez, 2006; Schraw, Crippen, \& Hartley, 2006). In MyAltis, the social content of instruction consists of traditional discussion forums and real time virtual interaction/chat between avatars (learners) collaborating on learning path assignments, sharing and exchanging information, knowledge, and opinions, and, hence, building their social network as they progress through the learning path. For instance, when unsure on how to proceed with the task, learners can secure help on an assignment in real-time from other avatars/learners present within the learning path. This mutual "mentoring" capacity appeals to students as it builds confidence and camaraderie that lasts beyond a single learning path.

We have found that students seldom feel alone within MyAltis. Because it is a multiuser environment, in addition to a virtual facilitator, students (and instructors) can observe avatars of 
other students/faculty present in the virtual center at the same time, and can initiate interaction in real time with any of them. They can decide to "go to the Theater" to watch a video together, or "go to the library" to read an article and discuss it. Besides of this sense of camaraderie, all students have been observed enjoying adding individual characteristics to their avatars and recognizing each other by their avatars in the virtual community they create as they progress through class. This is beneficial in a distance learning environment, where online interaction in the form of discussion boards/forums is the chief interaction available to students and instructors.

\section{Implications for Leadership Educators}

In their study of using games for enhancing Strategic Management instruction, Azriel, Erthal, and Starr (2005) discovered that games motivate students to actively participate in the learning process, encourage teamwork, and are effective for reviewing the studied material. Consequently, Azriel et al. (2005) called for incorporating new teaching practices into traditional instruction. Relatedly, a recent NMS Horizon Report (2012) points out that instructors may not recognize benefits of gamifying educational content, yet it is acknowledged that gaming sparks student interest in the subject of the game (e.g., multiplayer online gamers spend 10-15 hours per week conducting online research related to their games). The actual experience shared here of utilizing gamified instruction for global leadership instruction supports Azriel et al. (2005) study and demonstrates that it is possible to meaningfully integrate informative component, roleplaying component, and social networking component into a gamified instruction.

Based on successful application of MyAltis in corporate training (Renault, Orange) in Europe, as well as on its appeal for digital technology savvy traditional graduate students with full-time university enrollment (an experience shared here), gamified instruction has a broad cross-generational and cross-cultural appeal. Specifically, students participating in MyAltis instruction consistently voice their excitement about their "cool experience" with gamified learning, and their engagement in the learning process is more active and indicative of increased knowledge retention. While our experiences utilizing MyAltis as a leadership education tool are positive on both the instructor and student side, any new tool requires time and effort to master-on both the instructor and student side. Still, further empirical research is needed to compare the learning outcomes when instruction is delivered through a gamified platform in general (such as and MyAltis), versus traditional instruction.

\section{Conclusion}

While the example explored here is limited to a specific gamified platform configured for a cross-cultural competency instruction in the global leadership education context, leadership educators are encouraged to experiment with existing gaming applications and consider integrating games and other innovative interactive technology with pedagogical content, within broader domains of leadership education. For instance, the NMS Horizon Report (2012) includes a sampling of applications that are developed by various organizations in assorted gaming domains to address specific instruction needs (analytics focused, subject-matter based, type of interaction based). The challenge for leadership educators and institutions of higher education is to identify gamified platforms comprehensive enough to offer a balanced combination of desirable and practical features: learner-centered environment, comprehensive performance 
analytics and gamified structure universally applicable to any desirable content to ensure cost efficiency.

As long as instructors are intentional and thoughtful about meaningfully aligning pedagogical content within the gamified platform, and as long as platform offers adequate digital instruction tools, integration can produce positive learner-centered outcomes that increase learners' excitement, engagement and improve knowledge retention. Considering growing acceptance of gaming as an instructional component, educators who are interested in integrating gaming into their instruction are encouraged to investigate existing gamified platforms to ensure they are robust enough to adequately serve both learners and instructors/administrators of learning process.

\section{References}

Adelman, L., Bresnick, T., Cohen, M., Riedel, S., Shastri, L., \& Thompson, B. (2000). Training critical thinking for the battlefield: Volume 1: Basis in cognitive theory and research (Cognitive Technologies Technical Report 00-2). Arlington, CA: Cognitive Technologies. Retrieved from https://pdfs.semanticscholar.org/df8a/67c8079d8844a37b7d812921e59d6a871a16.pdf

AMA. (2012). Developing Successful Global Leaders. The third annual study of challenges and opportunities (in collaboration with i4CP and Training Magazine). Retrieved from https://cdns3.trainingindustry.com/media/13267033/ama_developing_global_leaders.pdf

Azriel, J., Erthal, M., \& Starr, E. (2005). Answers, questions, and deceptions: What is the role of games in business education? Journal of Education for Business, 81(1), 9-14.

Beechler, S., \& Javidan, M. (2007). Leading with a global mindset. In Javidan, M., Steers, R.\& Hitt, M. (Eds.). Advances in international management: The global mindset. Oxford: Elsevier/JAI Press

Bird, A., Medenhall, M., Oddou, G., \& Stevens, M. (2010). Defining the content domain of intercultural competence for global leaders. Journal of Managerial Psychology, 25(8), 810-828.

Brown, A. L. (1987). Metacognition, executive control, self-regulation, and other more mysterious mechanisms. In F. Weinert \& R. Kluwe (Eds.), Metacognition, motivation, and understanding (pp. 65-116). Hillsdale, NJ: Lawrence Erlbaum Associates

Burgos, D., Tattersall, C., \& Koper, R. (2007). Re-purposing existing generic games and simulations for e-learning. Computers in Human Behavior, 23(6), 2656-2667.

Case, R. (2005). Moving critical thinking to the main stage. Education Canada, 45(2), 45-49. 
Damian, I., Baur, T., Lugrin, B., Gebhard, P., Mehlmann, G., \& André, E. (2015). Games are better than books: In-Situ comparison of an interactive job interview game with conventional training. In C. Conati, N. Heffernan, A. Mitrovic, \& M. Verdejo (Eds.), Artificial Intelligence in education. AIED 2015. Lecture Notes in Computer Science, vol. 9112. Springer

Day, D. V., Fleenor, J. W., Atwater, L. E., Sturm, R. E., \& McKee, R. A. (2014). Advances in leader and leadership development: a review of 25 years of research and theory. The Leadership Quarterly, 25, 63-82.

Deloitte Consulting, LLP. (2012). Leadership development factbook 2012: Benchmarks and trends in U.S. leadership development. Bersin by Deloitte. Retrieved from http://www.bersin.com/Practice/Detail.aspx?id=15587

Deloitte Consulting LLP. (2014). Leadership development factbook: Benchmarks and trends in U.S. leadership development. Bersin by Deloitte. Retrieved from http://www.bersin.com/Practice/Detail.aspx?id=17478

Dickey, M. D. (2005). Engaging by design: How engagement strategies in popular computer and video games can inform instructional design. Educational Technology Research and Development, 53(2), 67-83.

Dillenbourg, P., Baker, M., Blaye, A., \& O’Malley, C. (1996). The evolution of research on collaborative learning. In E. Spada \& P. Reiman (Eds.), Learning in humans and machine: Towards an interdisciplinary learning science, 189-211. Oxford: Elsevier.

Earley, P., \& Ang, S. (2003). Cultural intelligence: Individual interactions across cultures. Palo Alto, CA: Stanford University Press.

Ellis, R. (2009). Field guide to learning management systems. American Society for Training and Development. Retrieved from http://www.astd.org/ /media/Files/Publications/LMS_fieldguide_20091

Ennis, R. H. (1985). A logical basis for measuring critical thinking skills. Educational Leadership, 43(2), 44-48.

Fitzimmons, J., Fitzsimmons, M., \& Bordoloi, S. (2014). Service management: Operations, strategy, information technology. ( $8^{\text {th }}$ Ed.). New York, NY: McGraw Hill Education

Flavell, J. (1976). Metacognitive aspects of problem solving. In L. Resnick (Ed.), The nature of intelligence, 231-236. Hillsdale, NJ: Erlbaum

Flavell, J. (1979). Metacognition and cognitive monitoring: A new area of cognitive developmental inquiry. American Psychologist, 34, 906-911. 
Flavell, J. (1987). Speculations about the nature and development of metacognition. In F. Weinert \& R. Kluwe (Eds.), Metacognition, Motivation and Understanding (pp. 21-29). Hillsdale, N.J.: L. Erlbaum Associates.

Gee, J. P. (2003). What video games have to teach us about learning and literacy. New York, NY: Palgrave Macmillan

Gee, J. (2008). Learning and games. In. K. Salen (Ed.), The ecology of games: Connecting youth, games, and learning. (21-40). Cambridge, MA: The MIT Press.

Geiwitz, J. (1994). Training metacognitive skills for problem solving. ARI research note 95-03. United States Army Research Institute for the Behavioral and Social Sciences. Retrieved from www.dtic.mil/cgi-bin/GetTRDoc?AD=ADA290310

Goldsmith, M., Walt, C., \& Doucet, K. (2000). New competencies for tomorrow's global leader. CMA Management, 73(10), 20-26.

Goryunova, E. (2016). Exploring metacognitive strategies utilized by bicultural global leaders for effective interaction across cultures. (Unpublished doctoral dissertation). Indiana Institute of Technology, Fort Wayne, IN

Guest, J. (2015). Reflections on ten years of using economic games and experiments in teaching. Cogent Economics \& Finance, 3, 111561.

Gurdijian, P., Halbeisen, T., \& Lane, K. (2014). Why leadership-development programs fail. McKinsey Quarterly. Retrieved from http://www.mckinsey.com/globalthemes/leadership/why-leadership-development-programs-fail

Guthrie, K., Phelps, K., \& Downey, S. (2011). Virtual worlds. A developmental tool for leadership education. Journal of Leadership Studies, 5(2), 6-13.

Hall, B. (2015). State of leadership development 2015: The time to act is now. Retrieved from http://www.ddiworld.com/DDI/media/trend-research/state-of-leadershipdevelopment_tr_brandon-hall.pdf?ext=.pdf

Hennessey, G. (1999). Probing the dimensions of metacognition: Implications for conceptual change teaching-learning. Paper presented at the annual meeting of the National Association for Research in Science Teaching, Boston, MA.

House, R., Hanges, P., Javidan, M., Dorfman, P., \& Gupta, V. (2004). Culture, leadership, and organizations: The GLOBE study of 62 societies. Thousand Oaks, CA: Sage.

Huebscher, J., \& Lendner, C. (2010). Effects of entrepreneurship simulation game seminars on entrepreneurs' and students' learning. Journal of Small Business and Entrepreneurship, 32(4), 543-554. 
Institute for Corporate Productivity (i4cp) (2014). Global Leadership Development: Preparing Leaders for a Globalized Market. Retrieved from http://www.amajapan.co.jp/e/pdf/2014GLDsurvey(E).pdf

Jones, T., \& Cuthrell, K. (2011). YouTube: Educational potentials and pitfalls. Computers in the Schools, 28(1), 75-78

Jenkins, D. M. (2012). Global critical leadership: Educating global leaders with critical leadership competencies. Journal of Leadership Studies, 6(2), 95-101.

Jenkins, D. M., Endersby, L., \& Guthrie, K. L. (2015). Leadership education 2050: Changing the spaces and faces of experience. In M. Sowcik, A. C. Andenoro, M. McNutt, \& S. E. Murphy (Eds.), Leadership 2050: Critical challenges, key contexts, and emerging trends (127-139). Bingley, UK: Emerald Group Publishing Limited.

Jenkins, D. M. (2016). Teaching leadership online: An exploratory study of instructional and assessment strategy use. Journal of Leadership Education, 15(2), 129-149. Retrieved from http://journalofleadershiped.org/index.php/volume-15-issue-2/431-teachingleadership-online-an-exploratory-study-of-instructional-and-assessment-strategy-use

Kolb, D. A. (1984). Experiential Learning. Experience as the source of learning and development. New Jersey: Prentice-Hall.

Kuhn, D. (2000). Metacognitive development. Current Directions in Psychological Science, 9(5), 178-181.

Lai, E. (2011). Critical thinking: Literature review. Pearson research report. Retrieved from http://images.pearsonassessments.com/images/tmrs/CriticalThinkingReviewFINAL.pdf

Lave, J. (1988). Cognition in practice: Mind, mathematics, and culture in everyday life. Cambridge, NY: Cambridge University Press.

Lei, J. (2010). Quantity versus quality: A new approach to examine the relationship between technology use and student outcomes. British Journal of Educational Technology, 41(3), 455-472

Martinez, M. E. (2006). What is metacognition? Phi Delta Kappan, 87(9), 696-699.

Mastroianni, B. (2016). How Generation Z is changing the tech world. CBS News. Retrieved from http://www.cbsnews.com/news/social-media-fuels-a-change-in-generations-withthe-rise-of-gen-z/

Mathan, S. A., Koedinger, K. R. (2005). Fostering the intelligent novice: Learning from errors with metacognitive tutoring. Educational Psychologist, 40(4), 257-265 
Mendenhall, M., Osland, J., Bird, A., Oddou, G., \& Maznevski, M. (2008). Global leadership: research, practice and development. New York, NY: Routledge.

Mendenhall, M., Reiche, B., Bird, A., Osland, J. (2012). Defining the 'global' in global leadership. Journal of World Business, 47(4), 493-503.

Molinsky, A. (2007). Cross-cultural code-switching: The psychological challenges of adapting behavior foreign cultural interactions. Academy of Management Review, 32(2), 622-640

Moody, A. (2010). Using electronic books in the classroom to enhance emergent literacy skills in young children. Journal of Literacy and Technology, 11(4), 22-52

Mor, S., Morris, M., Joh, J. (2013). Identifying and training adaptive cross-cultural management skills: The crucial role of cultural metacognition. Academy of Management Learning \& Education, 12(3), 453-475.

Moro, C., \& Tubbs, S. (2004). Identifying global leadership competencies. An exploratory study. Journal of American Academy of Business, 5(1/2), 80-87.

New Media Consortium. (2012). Horizon report: 2012 Higher Education Edition. Retrieved from http://www.nmc.org/pdf/2012-horizon-report-HE.pdf)

Papaleontiou-Louca, E. (2003). The concept and instruction of metacognition. Teacher Development, $7(1), 9-30$

Papastergiou, M. (2009). Digital game-based learning in high school computer science education: impact on education effectiveness and student motivation, Computers \& Education, 52(1), 1-12.

Paul, R. (1993). Critical thinking: How to prepare students for a rapidly changing world. $\left(3^{\text {rd }}\right.$ ed.). Santa Rosa, CA: Foundation for Critical Thinking.

Phelps, K. (2012). Leadership online: expanding the horizon. New Directions for Student Services, 140, 65-75.

Prensky, M. (2001). Digital natives, digital immigrants. On the Horizon (MCB University Press, 9(6). Retrieved from http://www.marcprensky.com/writing/Prensky\%20\%20Digital\%20Natives, \%20Digital\%20Immigrants\%20-\%20Part1.pdf

Rideout, M., Foehr. U., Roberts, D. (2010). Generation M2. Media in the Lives of 8-to-18-yearolds. A Kaiser Family Foundation Study. Retrieved from http://files.eric.ed.gov/fulltext/ED527859.pdf

Schraw, G., Dennison, R. S. (1994). Assessing metacognitive awareness. Contemporary Educational Psychology, 19, 460-475. 
Schraw, G., Crippen, K. J., \& Hartley, K. (2006). Promoting self-regulation in science education: Metacognition as part of a broader perspective on learning. Research in Science Education, 36, 111-139.

SpilGames. (2013). State of online gaming report. Retrieved from http://auth-83051f68-ec6c44e0-afe5bd8902acff57.cdn.spilcloud.com/v1/archives/1384952861.25_State_of_Gaming_2013_U S_FINAL.pdf.

Sternberg, R. J. (1985). Beyond IQ: A triarchic theory of human intelligence. New York, NY: Cambridge University Press.

The Chronicle of Higher Education. (2010). Information technology on campuses: By the numbers. Retrieved from http://www.chronicle.com/article/Info-Tech-onCampuses/127405)

Thomas, D., Elron, E., Stahl, G., Ekelund, B., Ravlin, E., Cerdin, J., Poelmans, S., Brislin, R., Pekerti, A., Aycan, Z., Maznevski, M., Au, K., \& Lazarova, M. (2008). Cultural intelligence: Domain and assessment. International Journal of Cross Cultural Management, 8(2), 123-143.

Torrente, J., Moreno-Ger, P., Martínez-Ortiz, I., \& Fernandez-Manjon, B. (2009). Integration and deployment of educational games in e-learning environments: The learning object model meets educational gaming. Educational Technology \& Society, 12(4), 359-371.

UNC Executive Development \& Human Capital Institute. (2015). UNC leadership survey 2015: compete and connect: Developing globally-competent leaders. Retrieved from http://www.kenan-flagler.unc.edu/ /media/Files/documents/executive-development/uncwhite-paper-developing-global-competence-final.pdf)

Urban B. (2012). A metacognitive approach to explaining entrepreneurial intentions. Management Dynamics, 21(2), 16-33.

U.S. Census. (2015). Millennials outnumber baby boomers and are far more diverse. Census Bureau Reports. Retrieved from https://www.census.gov/newsroom/pressreleases/2015/cb15-113.html

Wang, C., Li, Y., \& Tzeng, Y. (2015). How to replicate the cognitive process in computer gamebased learning units. Information Technology \& People, 28(2), 327-343.

Wideman, H., Owston, R., Brown, C., Kushniruk, A., Ho, F., \& Pitts, K. (2016). Unpacking the potential of educational gaming: A new tool for gaming research. Simulation \& Gaming, $38(1), 10-30$

Willingham, D. (2008). Critical thinking. Why is it so hard to teach? Arts Education Policy Review, 109(4), 21-29. 
Wolfe, J. (1997). The Effectiveness of business games inn strategic management coursework. Simulation \& Gaming, 38, 360-376.

\section{Author Biographies}

Elizabeth Goryunova, Ph.D., is an Assistant Professor of Leadership \& Organizational Studies at the University of Southern Maine. Her scholarship explores the integration of metacognitive strategies, critical thinking, and innovative instruction into global leadership development and women leadership. Elizabeth co-authored the Handbook of Research on Gender and Leadership (2017).

Dan Jenkins, Ph.D., is Chair and Associate Professor of Leadership \& Organizational Studies at the University of Southern Maine. He received his doctorate in Curriculum \& Instruction from the University of South Florida. Dan has published more than 30 articles and facilitated dozens of workshops around the world on leadership education, pedagogy, curriculum, and course design. Dan is a past chair of the ILA Leadership Education Member Interest Group, co-chair of the ILA Leadership Education Academy, and former Secretary of the Association of Leadership Educators. 